\title{
ReGent Advances in Fetal Near Infrared SPECTROSCOPY
}

\author{
Donato D'Antona, ${ }^{\dagger}$ Clive J. Aldrich, ${ }^{\dagger}$ Patrick O'Brien, ${ }^{\dagger}$ Sally Lawrence, ${ }^{\dagger}$ \\ David T. Delpy, ${ }^{\dagger}$ and John S. Wyatt* \\ †University College London Medical School, Departments of Obstetrics and Gynecology, London, \\ United Kingdom, WC1 6JA; ${ }^{\dagger}$ University College London Medical School, Physics Department, London, \\ United Kingdom WC1 6JA; ${ }^{*}$ University College London Medical School, Pediatrics Department, \\ London, United Kingdom WC1 6JA \\ (Paper NIR-13 received June 10, 1996; revised manuscript received Oct. 31, 1996; accepted for publication Dec. 21, 1996.)
}

\begin{abstract}
Fetal brain injury resulting from hypoxia and ischemia during labor remains an important cause of death and long-term disability. However, little is known about fetal brain oxygenation and hemodynamics. There are currently no satisfactory clinical techniques for fetal monitoring and there remains a need for a new method to assess brain oxygenation. Fetal near infrared spectroscopy (NIRS) is a new technique that allows noninvasive observation of changes in the cerebral concentrations of oxyhemoglobin and deoxyhemoglobin to be made during labor. A specially designed optical probe is inserted through the dilated cervix and placed against the fetal head. It is then possible to compare changes in NIRS data with other observations of fetal conditions, such as fetal heart rate and acid-base status. (๑) 1997 Society of Photo-Optical Instrumentation Engineers.
\end{abstract}

Keywords near infrared spectroscopy; fetal; brain; oxygenation.

\section{INTRODUCTION}

Although the incidence of intrapartum hypoxicischemic brain injury remains controversial, ${ }^{1,2}$ it continues to be an important cause of mortality and long-term disability. There are currently no entirely satisfactory techniques for intrapartum fetal surveillance in clinical practice. The need for another method of fetal monitoring has been recognized for many years; ${ }^{3,4}$ in particular a method that can directly assess fetal brain oxygenation is required. ${ }^{5}$

Near infrared spectroscopy (NIRS) provides a novel and potentially valuable noninvasive technique for investigating the fetal brain during labor. It is capable of providing data about several important variables of cerebral oxygenation and hemodynamics, ${ }^{6-8}$ and since 1985 it has been used as a research tool for investigating the brain of the newborn infant. More recently the technique has been adapted to monitor the human fetal brain during labor., ${ }^{9,10}$

\section{METHODS}

Measurements have been obtained from the fetal head during labor using modifications of a specially designed fetal probe (size: $8 \times 3 \times 1.5 \mathrm{~mm}$ ) (Figure 1). This is molded from flexible silicone rubber and contains both the transmitting and receiving optical fiber bundles at a fixed distance of between 4 and

Current affiliation of Donato D'Antona: University of Sassari, Department of Obstetrics and Gynecology, Viale S. Pietro n. 12, Sassari, Italy.

Address all correspondence to Donato D'Antona. E-mail: ginecol@ssmain.uniss.it
$3.5 \mathrm{~cm} .{ }^{8}$ Following rupture of the amniotic membranes, the probe can be inserted through the dilated cervix $(\geqslant 3 \mathrm{~cm})$ and applied against the fetal head. The probe is then maintained in position by a combination of continuous negative pressure (150 $\mathrm{mm} \mathrm{Hg}$ ) provided by a modified wall suction apparatus and maternal tissue pressure. (Since nearinfrared light is highly scattered within the brain, the exact anatomical position of the probe on the head is not critical, but care is taken to avoid the face and ears.)

Near infrared light, at four different wavelengths between 777 and $913 \mathrm{~nm}$, is transmitted. Changes in attenuation at each wavelength are detected continuously and converted into changes in the cerebral concentrations of oxyhemoglobin and deoxyhemoglobin $\left(\left[\mathrm{HbO}_{2}\right]\right.$ and $\left.[\mathrm{Hb}]\right)$ using a previously established algorithm. ${ }^{11-14}$ Changes in the total cerebral hemoglobin concentration $\left(\left[\mathrm{Hb}_{\text {tot }}\right]\right)$ may be obtained from the sum of $\left[\mathrm{HbO}_{2}\right]$ and $[\mathrm{Hb}]$, and the hemoglobin oxygenation index $\left[\mathrm{Hb}_{\text {diff }}\right]$ is obtained from the difference $\left(\left[\mathrm{HbO}_{2}\right]-[\mathrm{Hb}]\right) \cdot{ }^{15}$ Measurements are displayed at the bedside and transferred to a portable computer for recording on computer disk for later analysis. Cardiotocograph (CTG) data are recorded simultaneously (Figure 2). Observations may be commenced immediately following insertion of the optical probe and, where feasible, are continued until the point of delivery of the fetal head.

1083-3668/97/\$10.00@1997 SPIE 


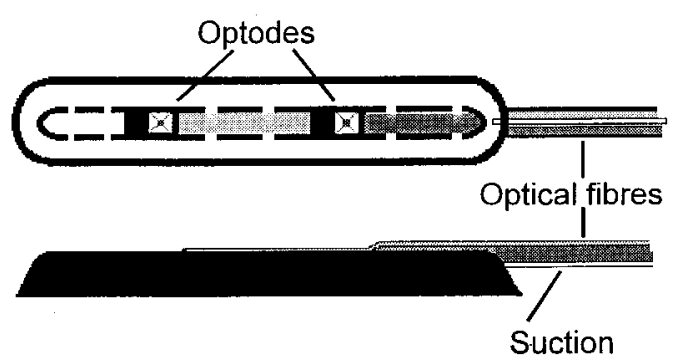

Fig. 1 Fetal NIRS probes.

\subsection{CALCULATION OF MEAN CEREBRAL OXYGEN SATURATION}

Large fluctuations in $\left[\mathrm{HbO}_{2}\right]$ and $[\mathrm{Hb}]$ are routinely observed during each uterine contraction due to changes in cerebral blood volume. When both $\left[\mathrm{HbO}_{2}\right]$ and $[\mathrm{Hb}]$ change in the same direction during a contraction, it is possible to calculate the mean cerebral oxygen saturation $\left(\mathrm{SmcO}_{2}\right)$ from the ratio between the changes in $\left[\mathrm{HbO}_{2}\right]$ and $\left[\mathrm{Hb}_{\text {tot }}\right]:$ :

$$
\mathrm{SmcO}_{2}=\frac{100 \times\left[\mathrm{HbO}_{2}\right]}{\left[\mathrm{HbO}_{2}+\mathrm{Hb}\right]} .
$$

For example, it can be seen that if the changes in $\left[\mathrm{HbO}_{2}\right]$ and $[\mathrm{Hb}]$ are equal, the mean saturation of the cerebral blood is $50 \%$. If it is assumed that $\mathrm{SmcO}_{2}$ is not changing rapidly, measurements may be analyzed over several contractions and a mean value obtained.

\section{FETAL OBSERVATIONS USING NIRS IN LABOR}

Continuous observations have been obtained for periods lasting from 7 to $666 \mathrm{~min}$ (median $132 \mathrm{~min}$ ). Data were considered suitable for analysis only if they exhibited a stable baseline without obvious

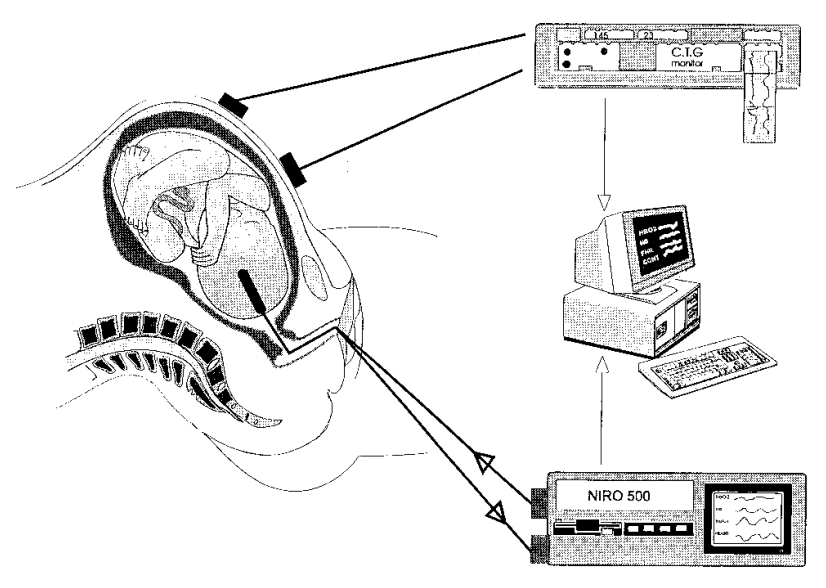

Fig. 2 Clinical equipment used for fetal intrapartum NIRS studies. movement artifacts on visual inspection. Satisfactory data were obtained during labor in approximately $85 \%$ of women in whom studies were attempted and on average less than $20 \%$ ( 0 to $40 \%$ ) of the signal during any one study was obscured by artifacts or interference.

All the studies were approved by the local committee on the ethics of human research, and informed written consent was obtained from each woman. No difficulty was experienced in positioning the probe on the fetal scalp; none of the mothers found optical monitoring uncomfortable, and the technique did not interfere with routine management during labor. In the majority of cases it was possible to make satisfactory measurements during changes in maternal position and even with the mother standing or walking. There were no complications associated with insertion or removal of the probe in any of the mothers and no fetal scalp trauma was observed. In addition, the power density of light from the transmitting fiber is approximately one order of magnitude below international safety standards for skin and eye exposure to laser light (IEC 825). There is therefore no possibility of light-induced damage to the fetal tissues.

\subsection{PRACTICAL PROBLEMS AND POTENTIAL SOURCES OF ERROR}

Any form of measurement made directly from the fetus during labor has to overcome problems of limited access, movement of the measuring device on the fetal scalp, and the large pressures exerted by uterine contractions. This is particularly true of NIRS and it may be difficult to first, obtain data and then second, to exclude artifacts when analyzing it. There are also several potential sources of error in the measurements of $\left[\mathrm{HbO}_{2}\right]$ and $[\mathrm{Hb}]$ obtained using this technique. The size of these errors is hard to ascertain at present but is believed to be small compared with the large size of the hemoglobin signal.

Although satisfactory NIRS data could be obtained in the majority of studies (Figure 3), a small number of studies failed because sufficient light could not be transmitted through the scalp and head (Figure 4). This was observed most frequently in features of Afro-Caribbean mothers due to the light-absorbing effects of thick black hair and dark skin. Occasionally this problem could be overcome by repositioning the probe over an area with less hair. Improving the optical performance of the NIRS system would be a long-term solution to this problem. The other main reason for failure to acquire satisfactory data was poor contact between the optodes and the fetal scalp, which was most frequently observed with rapid descent of the fetal head, during difficult vaginal examinations, and during rapid changes in maternal position. Poor optical contact could be detected by an unstable baseline with rapid and abrupt changes in the NIRS signals. Another important consideration is the con-

16 Journal of Biomedical OPtics • January 1997 • Vol. 2 No. 1 


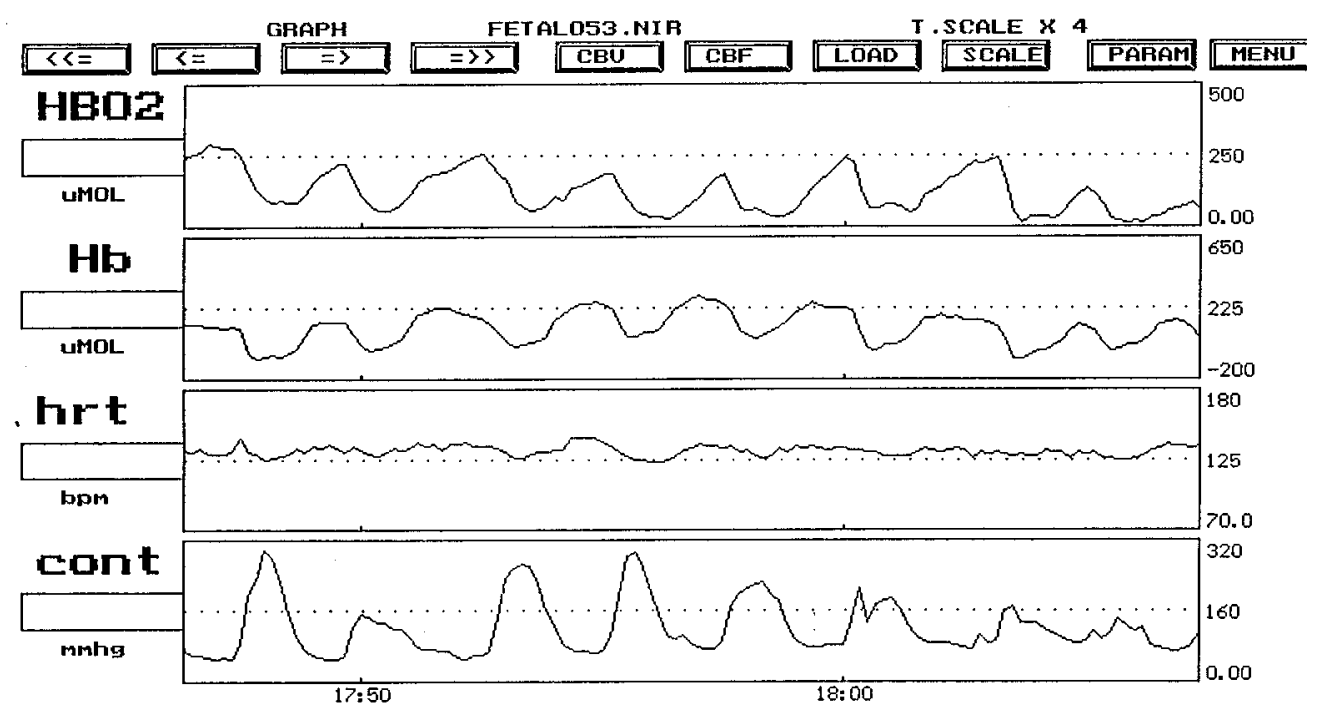

Fig. 3 Example of a "good quality" NIRS signal.

tribution of skin and bone to the NIRS signals. In the fetal head, however, this contribution is likely to be small $(<10 \%)$ because the superficial tissues are relatively thin. ${ }^{16}$ As mentioned earlier, an algorithm is used to convert changes in light attenuation into changes in chromophore concentration and this may also be a possible source of error, work is being undertaken to allow more accurate quantification of data.

With our current apparatus it is not possible to detect very small and gradual changes in optode position, and the possibility remains that small changes in optode position and or pressure on the fetal probe during uterine contractions may alter the interoptode space, leading to a change in the total optical path length. Because the software has been programmed to assume a constant path length, any change in attenuation of light is interpreted as a change in concentration of chromophore. Consequently, any change in interoptode space could theoretically account for some or all of the typical contraction-related changes in concentration of oxy- and deoxyhemoglobin recorded with NIRS. Hamilton et al. recently used NIRS to study a dead fetus during labor ${ }^{17}$ and recorded concentration changes similar in character and magnitude to those previously described in live fetuses (mean cerebral oxygen saturation values were on the order of $70 \%$ ). They argued that because oxygen saturation in a dead fetus must be close to zero, these apparent concentration changes were probably due to movement artifacts. They proposed that the similar changes seen in live fetuses might also be due solely to movement.

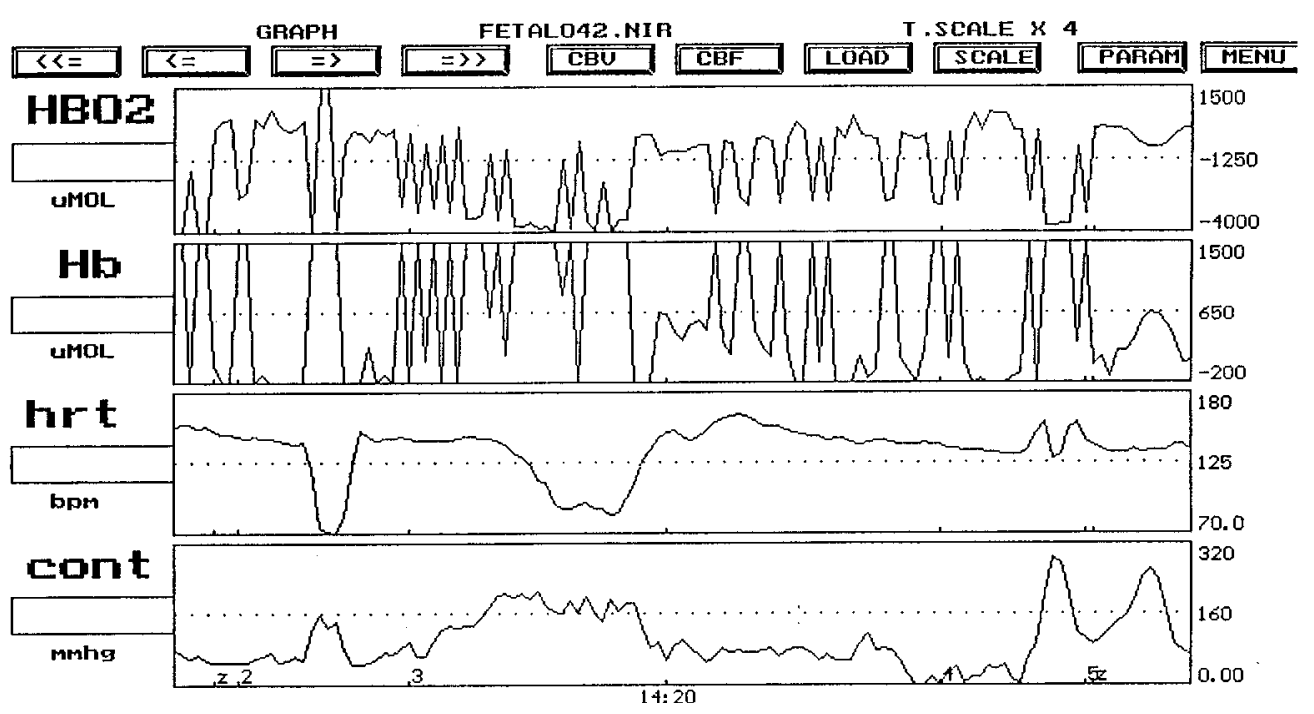

Fig. 4 Example of a "noisy" NIRS signal in an Afro-Caribbean fetus. 


\subsection{INTENSITY-MODULATED OPTICAL SPECTROMETRY}

It was clear that continuous measurement of optical path length during NIRS measurements was necessary. In order to address this problem, an intensitymodulated optical spectrometer (IMOS) was designed and built by the Department of Medical Physics at University College Hospital, London, (UCH) ${ }^{18}$ In IMOS, the continuous laser sources are intensity modulated. The phase shift between the light entering and exiting the tissue is recorded and can be related to the total optical path length, ${ }^{19}$ allowing continuous measurement of path length as well as conventional NIRS data. In this way, the attenuation changes can be corrected for path length changes in real time and the contribution of movement artifacts to the apparent changes in oxyand deoxyhemoglobin concentration can be quantified.

Initial studies of live fetuses at $\mathrm{UCH}$ are encouraging. Four fetuses have been studied during the first stage of labor for a mean duration of $32 \mathrm{~min}$ (10 contractions). Between contractions, the mean path length was $16.8 \mathrm{~cm}$, which was broadly equivalent to the path length previously calculated from the term "differential path length factor X interoptode space." The influence of path length changes is small, with maximum variation of less than $12 \%$ and a mean variation of only a few percent. Variations of similar magnitude were observed in all cases where no gross movement artifact occurred. These changes contrasted with the 40 to $50 \%$ changes seen in apparent chromophore concentration. $\mathrm{SmcO}_{2}$ was calculated using both path lengthcorrected and uncorrected data; there was no significant difference between the two. The conclusion from these preliminary data is that while path length changes do occur during contractions, they are small and have no clinically significant effect on changes in the calculated values of oxy- and deoxyhemoglobin concentration.

\subsection{LATE FETAL HEART RATE DECELERATIONS AND CHANGES IN CEREBRAL OXYGENATION}

The use of continuous electronic fetal heart rate monitoring (EFM) during labor has achieved widespread acceptance for fetal surveillance since its introduction into clinical practice in the 1960s. However, it has not been shown to be associated with a clear reduction in hypoxic-ischemic brain injury, and difficulties of interpretation have led to an increase in the frequency of operative deliveries. ${ }^{20}$ Little is known about the relationship between fetal heart rate (FHR) changes and the oxygenation of the fetal brain. Of the three principal types of FHR decelerations that have been identified during labor (early, variable, and late), late decelerations have been shown to have the greatest clinical significance in predicting fetal hypoxia and acidemia. ${ }^{20}$
We therefore investigated changes in cerebral oxygenation during contractions in which late fetal heart rate decelerations occurred, compared with contractions during which there was no alteration in the FHR.

Data from 10 fetuses who had had late fetal heart rate decelerations during the final hour of the first stage of labor were analyzed. ${ }^{21}$ Changes in the cerebral concentrations of $\left[\mathrm{HbO}_{2}\right],[\mathrm{Hb}],\left[\mathrm{Hb}_{\text {tot }}\right]$, and $\left[\mathrm{Hb}_{\text {diff }}\right]$ were measured before, during, and after contractions with late fetal heart rate decelerations, and compared with changes during contractions in the same fetuses with no alteration of heart rate. Although changes during the contractions were the same in both groups, after the contraction there were significant decreases in $\left[\mathrm{HbO}_{2}\right]$ and a significant rise in $[\mathrm{Hb}]$ in association with the late fetal heart rate decelerations compared with the same period following control contractions. The decrease in cerebral oxygenation appeared to occur simultaneously with the delayed fall in fetal heart rate. Representative data from one fetus showing changes in NIRS measurements during a control contraction and a contraction associated with a late deceleration are illustrated in Figure 5. These data are consistent with the hypothesis that late fetal heart rate decelerations are caused by a bolus of deoxygenated blood passing from the placenta in the umbilical vein to the fetus. ${ }^{22}$

\subsection{RELATIONSHIP BETWEEN MEAN CEREBRAL OXYGEN SATURATION $\left(\mathrm{SMCO}_{2}\right)$ AND FETAL ACID-BASE STATE AT BIRTH}

Until recently, the only practical means of assessing fetal response to intrapartum hypoxia have been measurements of the fetal blood $\mathrm{pH}$ either before (scalp blood sample) or at birth (analysis of umbilical cord blood). In one series of studies, a total of 45 women were monitored to within $20 \mathrm{~min}$ of delivery. In 37 fetuses it was possible to calculate a mean value for $\mathrm{SmcO}_{2}$ over a 10 -min period in the $30 \mathrm{~min}$ prior to delivery. ${ }^{23}$ At delivery, samples of blood were immediately taken from the umbilical artery and vein and analyzed using an automated blood gas analyzer (ABL300; Radiometer, Copenhagen, Denmark). Figure 6 illustrates the relations between $\mathrm{SmcO}_{2}$ and $\mathrm{pH}$ and base deficit (BD). It can be seen that a highly significant positive relationship was observed between $\mathrm{SmcO}_{2}$ and umbilical artery $\mathrm{pH}$, and a highly significant negative correlation with BD. Similar relationships were found when samples were obtained from the umbilical vein. The majority of the babies were born in good condition and no clear correlation was observed between $\mathrm{SmcO}_{2}$ and Apgar scores at either 1 or $5 \mathrm{~min}$.

These data confirmed the expected relationship between fetal cerebral oxygenation prior to delivery and acidemia in the umbilical vessels at birth. The degree of fetal acidemia at birth is strongly influ- 

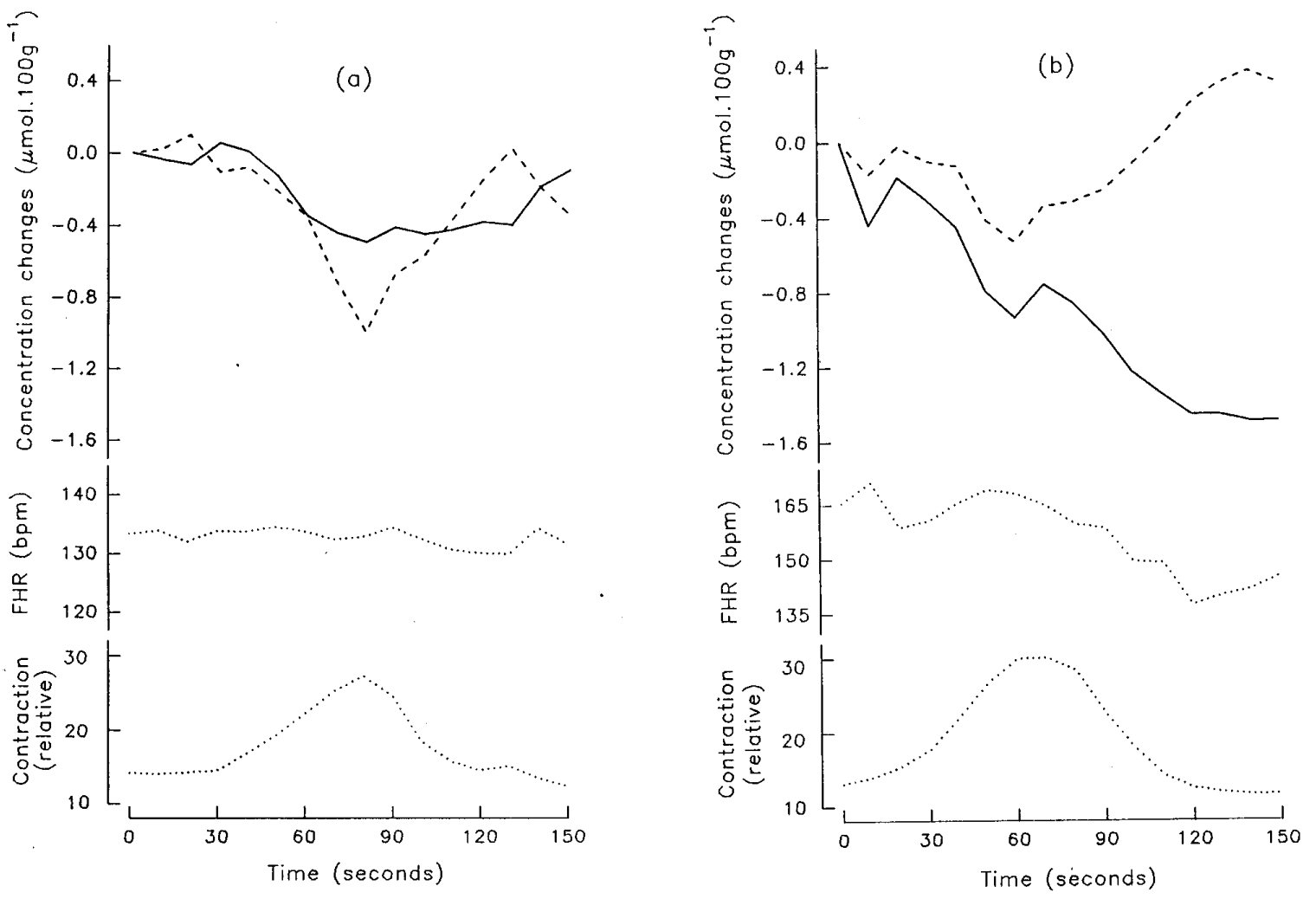

Fig. 5 Changes from baseline in oxyhemoglobin $\left[\mathrm{HbO}_{2}\right]$ (solid line) and deoxyhemoglobin [Hb] (dashed line) concentrations in a fetus with (a) no alteration in FHR and (b) a late FHR deceleration.

enced by the adequacy of the exchange of oxygen and carbon dioxide between the maternal and fetal circulations during labor. If gas exchange becomes impaired during labor, by cord compression or hypertonic uterine activity, for example, a complex series of metabolic adaptations ensues. Initially a respiratory acidemia develops due to an increase in fetal blood $\mathrm{pCO}_{2}$. As the fetal $\mathrm{pO}_{2}$ declines, the tissue intracellular oxygen concentration falls, leading to anaerobic metabolism of glucose and glycogen, and if adequate stores are present, lactic acid accumulates within the bloodstream, which is reflected by a further fall in the $\mathrm{pH}$ and an increase in the base deficit. In this study, low values of $\mathrm{SmcO}_{2}$ were associated with an acidemia, with a contribution from both respiratory and metabolic components.

The mean value for $\mathrm{SmcO}_{2}$ in all 37 fetuses was $46 \%$ (range 21 to $71 \%$ ). $\mathrm{SmcO}_{2}$ determined by NIRS represents an average saturation of blood within the brain and includes a contribution from all vascular components. Since the venous compartment is likely to be the largest and most distensible compartment within the cranium, it is likely that $\mathrm{SmcO}_{2}$ will most closely approximate the mixed cerebral venous saturation.

These preliminary data suggest that NIRS may have the potential to detect fetuses at increased risk of acidemia at delivery, but much larger studies will be necessary before the likely clinical value of the technique for intrapartum surveillance of the high-risk pregnancy can be assessed.

\subsection{OTHER STUDIES USING NIRS DURING LABOR}

In clinical practice, the value of administering maternal oxygen to improve fetal oxygenation during labor remains controversial. A study to investigate the effects of maternal oxygen administration during normal labor in 10 term fetuses showed that a significant rise in cerebral oxygenation occurred within $15 \mathrm{~min}$ of $60 \%$ oxygen breathing, and $\mathrm{SmcO}_{2}$ rose from 43.9 (SD 6.3) to $57.3 \%$ (SD 5.6). These changes were reversed rapidly when maternal oxygen breathing ceased. ${ }^{24}$ Further studies are required to determine under what circumstances maternal oxygen breathing might be clinically used, and this study suggests that NIRS is the method of choice for assessing the fetal response.

In another series of studies, we investigated the effect of a nuchal cord (umbilical cord around the neck) upon fetal cerebral hemodynamics and oxygenation during labor. ${ }^{25}$ For these fetuses there were significantly more contractions $(40.2 \%$; $\mathrm{SD}$ 19.5) associated with an increase in total hemoglo- 

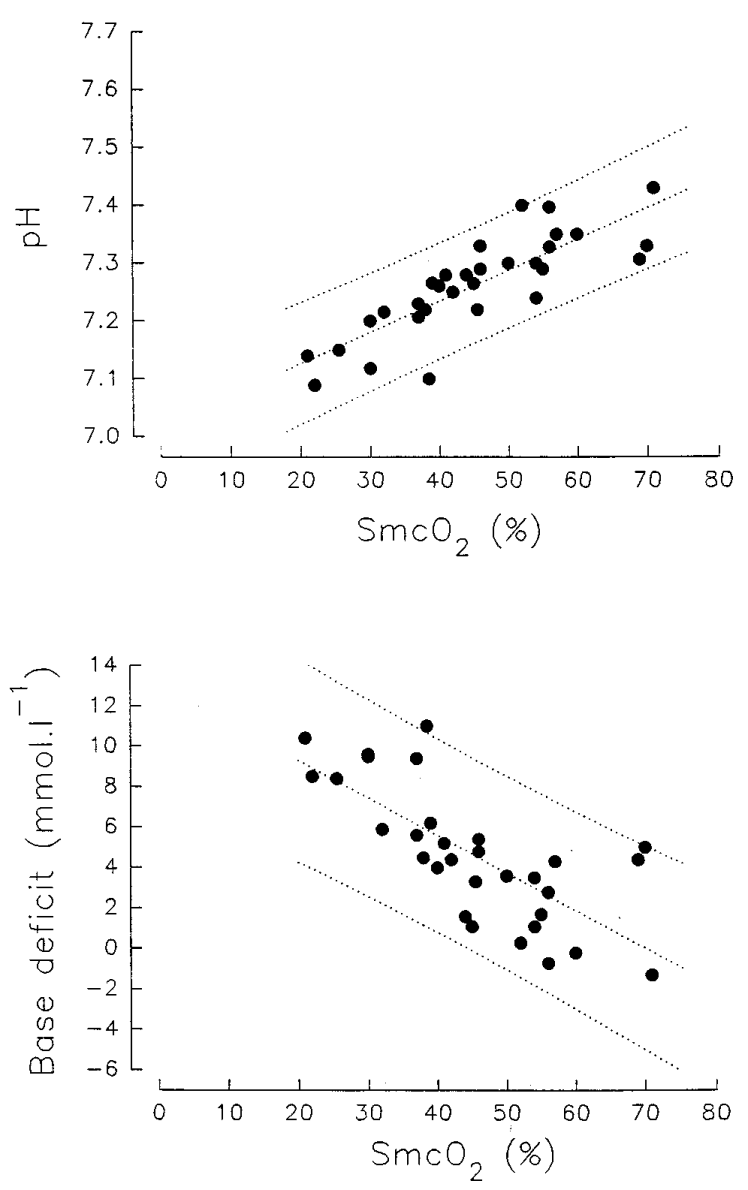

Fig. 6 The relation between fetal $\mathrm{SmcO}_{2}$ measured within $30 \mathrm{~min}$ of delivery and umbilical artery $\mathrm{pH}$ and $\mathrm{BD}$ at birth. The regression line and $95 \%$ confidence interval of the data points are included. bin concentration compared with the control fetuses without a nuchal cord (5.9\%; SD 7.1) (Figure 7). During a uterine contraction, a pressure gradient exists between the head and thorax, and we have previously suggested that this results in blood being mechanically squeezed from the cerebral venous compartment, with a consequent reduction in cerebral blood volume. ${ }^{8}$ The presence of a nuchal cord appears to interfere with this process. One possible explanation for this observation is transient compression of the jugular veins of the neck by the umbilical cord during uterine contractions. If the arterial blood supply to the brain was maintained during the uterine contraction, the cerebral blood volume would increase as long as the venous drainage of the head was obstructed.

Additional studies have evaluated the effect of maternal posture (moving from the left lateral to supine position) ${ }^{26}$ and maternal pushing during labor $^{27}$ on fetal cerebral oxygenation and hemodynamics. Both have been shown to result in a significant reduction of cerebral oxygenation.

\section{CONCLUSION}

Although experience remains limited, the studies that have been conducted indicate that NIRS has great potential for investigating human fetal cerebral oxygenation and hemodynamics during labor. Data from our recent experience with fetal NIRS indicate that it is clinically feasible, safe, acceptable to mothers, and causes minimal interference with routine midwifery and medical care on the labor

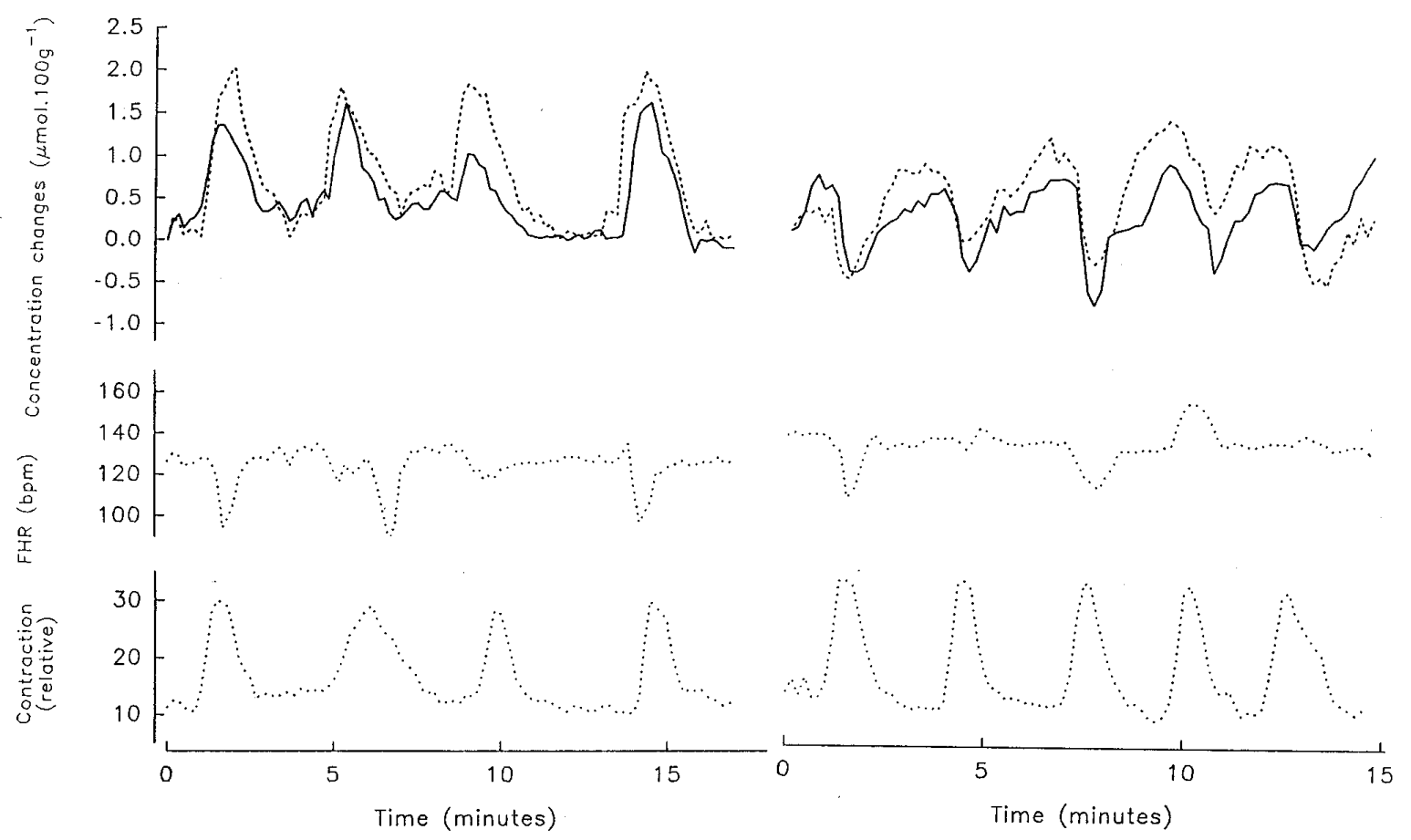

Fig. 7 Representative changes in $[\mathrm{Hb}]$ (dotted line) and $\left[\mathrm{HbO}_{2}\right]$ (solid line) concentrations, $\mathrm{FHR}$, and uterine contractions in (a) a fetus with a nuchal cord and (b) a control fetus. 
ward. The probe is simple to insert once the amniotic membranes are ruptured, and continuous quantitative measurements of changes in cerebral hemoglobin and deoxyhemoglobin concentration and $\mathrm{SmcO}_{2}$ can be obtained from early in labor up to the point of delivery and beyond. With existing equipment, satisfactory data can be obtained during labor in approximately $90 \%$ of women who are selected for study (although this figure is strongly influenced by ethnic race). Continuous recordings can be obtained throughout labor in the majority of studies and on average less than $20 \%$ of the signal is obscured by artifacts or interference.

The future clinical role of fetal NIRS remains open to speculation, but the technique has remarkable potential as a technique for intrapartum fetal surveillance, leading to an improved understanding of the effects of normal and abnormal labor on the fetal brain.

\section{REFERENCES}

1. E. Blair and F. J. Stanley, "Intrapartum asphyxia: a rare cause of cerebral palsy," J. Pediatr. 112, 515-519 (1988).

2. A. Johnson, "Cerebral palsy and birth: is there a relationship?" in Intrapartum Fetal Surveillance, J. A. D. Spencer and R. H. T. Ward, Eds., pp. 191-197, RCOG Press, London (1993).

3. P. J. Steer and M. C. Carter, "Cardiotocographs at a distance," Br. Med. J. 299, 933-934 (1989).

4. J. Neilson, "Cardiotocographs during labour," Br. Med. J. 306, 347-348 (1993).

5. R. E. Myers, "Two patterns of perinatal brain damage and their conditions of occurrence," Am. J. Obstet. Gynecol. 112, 246-276 (1972).

6. J. S. Wyatt, "Near infrared spectroscopy: investigation of perinatal brain injury," Biol. Neonate 62, 290-294 (1992).

7. L. N. Livera, S. A. Spencer, M. S. Thorniley, Y. A. Wickramasinghe, and P. Rolfe, "Effects of hypoxaemia and bradycardia on neonatal cerebral haemodynamics," Arch. Disease Child. 66, 376-380 (1991).

8. H. Fahnenstich, S. Schmidt, S. Spaniol, and S. Kowalewski, "Relative changes in oxyhemoglobin, deoxyhemoglobin and intracranial blood volume during surfactant replacement therapy in infants with respiratory distress syndrome," Develop. Pharm. Therap. 17, 150-153 (1991).

9. P. M. S. O'Brien, P. M. Doyle, and P. Rolfe, "Near infrared spectroscopy in fetal monitoring," Br. J. Hosp. Med. 49, 483487 (1993).

10. D. M. Peebles and J. S. Wyatt, "Near infrared spectroscopy and intrapartum fetal monitoring," Contemp. Rev. Obstet. Gynaecol. 5, 124-129 (1993).

11. J. S. Wyatt, M. Cope, D. T. Delpy, P. van der Zee, S. R. Arridge, A. D. Edwards, and E. O. Reynolds, "Measurement of optical pathlength for cerebral near infrared spectroscopy in newborn infants," Dev. Neurosci. 12, 140-144 (1990).

12. R. Araki and I. Nashimoto, "Multicomponent analysis of near infrared spectra of anaesthetised rat head: quantitative multivariate analysis of haemoglobin and cytochrome oxidase by non-negative least squares method," Adv. Exp. Biol. 248, 11-20 (1989).

13. P. van der Zee, M. Cope, S. R. Arridge, M. Essenpreis, L. A. Potter, A. D. Edwards, J. S. Wyatt, D. C. McCormik, S. C.
Roth, and E. O. Reynolds, "Experimentally measured optical pathlengths for the adult head, calf and forearm and the head of the newborn infant as a function of interoptode spacing," Adv. Exp. Med. Biol. 316, 143-153 (1992).

14. M. Essenpreis, C. Elwell, M. Cope, S. R. Arridge, M. Essenpreis, D. T. Delpy, and E. O. Reynolds, "Spectral dependence of temporal point spread functions in human tissues," Appl. Opt. 32, 418-425 (1993).

15. J. S. Wyatt, M. Cope, D. T. Delpy, S. Wray, and E. O. Reynolds, "Quantification of cerebral oxygenation and haemodynamics in sick newborn infants by near infrared spectroscopy," Lancet 2, 1063 (1986).

16. J. S. Wyatt, M. Cope, D. T. Delpy, C. E. Richardson, A. D. Edwards, S. Wray, and E. O. Reynolds, "Quantification of cerebral blood volume in human infants by near infrared spectroscopy," J. Appl. Physiol. 68, 1086-1091 (1990).

17. R. J. Hamilton, P. M. S. O'Brien, Y. A. B. D. Wickramasinghe, and P. Rolfe, "Intrapartum fetal cerebral near infrared spectroscopy: apparent change in oxygenation demonstrated in a non viable fetus," Br. J. Obstet. Gynaecol. 102, 1004-1007 (1995).

18. A. Duncan, T. Whitlock, M. Cope, and D. T. Delpy, "A multiwave wideband intensity modulated spectrometer for near IR spectroscopy and imaging," Proc. SPIE 1888, 248-257 (1993).

19. S. R. Arridge, M. Cope, and D. T. Delpy, "The theoretical basis for the determination of optical pathlength in tissue: temporal and frequency analysis," Phys. Med. Biol. 37, 15311560 (1992).

20. I. Ingemarsson, E. Ingemarsson, and J. A. D. Spencer, "Uniform decelerations," in Fetal Heart Rate Monitoring-A Practical Guide, I. Ingemarsson, E. Ingemarsson, and J. A. D. Spencer, Eds., pp. 123-152, Oxford Univ. Press, Oxford (1993).

21. C. J. Aldrich, D. D'Antona, J. A. D. Spencer, J. S. Wyatt, D. M. Peebles, D. T. Delpy, and E. O. Reynolds, "Late fetal heart rate decelerations and changes in cerebral oxygenation measured by near infrared spectroscopy during the first stage of labour," Br. J. Obstet. Gynaecol. 102, 9-13 (1995)

22. R. E. Myers, E. Mueller-Heubach, and K. Adamsons, "Predictability of the state of fetal oxygenation from a quantitative analysis of the components of late deceleration," Am. J. Obstet. Gynecol. 115, 1083-1094 (1973).

23. C. J. Aldrich, D. D'Antona, J. A. D. Spencer, and J. S. Wyatt, "Near infrared spectroscopy used in the assessment of intrapartum fetal cerebral oxygenation," Contemp. Rev. Obstet. Gynecol. 7, 71-76 (1995).

24. C. J. Aldrich, J. S. Wyatt, J. A. D. Spencer, D. M. Peebles, D. T. Delpy, and E. O. R. Reynolds, "The effect of maternal oxygen administration on human fetal cerebral oxygenation measured during normal labour by near infrared spectroscopy," Br. J. Obstet. Gynaecol. 101, 509-513 (1994).

25. D. D'Antona, C. J. Aldrich, J. A. D. Spencer, D. T. Delpy, E. O. R. Reynolds, and J. S. Wyatt, "Effect of nuchal cord on fetal cerebral haemodynamics and oxygenation measured by near infrared spectroscopy during labour," Eur. J. Obstet. Gynecol. Reprod. Biol. 59, 205-209 (1995).

26. C. J. Aldrich, D. D'Antona, J. A. D. Spencer, J. S. Wyatt, D. M. Peebles, D. T. Delpy, and E. O. Reynolds, "The effect of maternal posture on fetal cerebral oxygenation during labour," Br. J. Obstet. Gynaecol. 102, 14-19 (1995).

27. C. J. Aldrich, D. D'Antona, J. A. D. Spencer, J. S. Wyatt, D. M. Peebles, D. T. Delpy, and E. O. Reynolds, "The effect of maternal pushing on fetal cerebral oxygenation and blood volume during the second stage of labour," Br. J. Obstet. Gynaecol. 102, 448-453 (1995). 